\title{
The Study of Historical Indoor Microclimate (HIM) to Contribute towards Heritage Buildings Preservation
}

\author{
Kristian Fabbri ${ }^{1,+}\left(\mathbb{D}\right.$, Marco Pretelli ${ }^{1,+}$ and Anna Bonora ${ }^{2, *,+} \mathbb{C}$ \\ 1 Department of Architecture, University of Bologna, 40126 Bologna, Italy \\ 2 Department of Architecture, University of Bologna, Viale Risorgimento, 40126 Bologna, Italy \\ * Correspondence: anna.bonora3@unibo.it \\ + These authors contributed equally to this work.
}

Received: 17 June 2019; Accepted: 30 July 2019; Published: 2 August 2019

\begin{abstract}
Knowledge of building techniques, materials and their decay is nowadays quite vast, as well as on the solutions and methodologies of a restoration project, which depends on the goal of the restoration itself. Even the choices on the new usage of historic buildings are often well considered. In the last few years, we have conducted some monitoring campaigns to obtain data related to four distinct buildings, differing in construction times, typology, location, current and historical uses. What has been discovered is that these buildings appear to be able to guarantee historical microclimates surprisingly overlapping to the parameters nowadays considered appropriate to conserve them and the historical patrimony they contain. In this article we show some explanatory results of four case studies from our research. The monitoring control, moreover, allowed us to develop the analysis further, from survey to virtual simulation. In this way it was possible to verify the effects of minimal variations in the architectural characteristics, such as opening or closing a window, covering an open yard, or else removing a cover, reducing the source of light etc. All of these managerial and architectural interventions have a significant effect on the indoor environment of buildings and can improve the conservation status of architecture, sometimes to such an extent that more costly and invasive restorations become unnecessary.
\end{abstract}

Keywords: heritage buildings; historical indoor microclimate; preservation; virtual; building simulation; environment; decision making; restoration; technology; minimal intervention

\section{Introduction}

In its modern meaning, restoration counts only a couple of centuries of history as a discipline in Europe, but since its beginning it has developed an incredibly detailed attention to the material facts of physical parts of buildings such as masonry, plaster, floors, finishing, etc. Nowadays, every restoration project stem from detailed research on history, based on archives, bibliographic and iconographic analyses, architectonic surveys with electronic instruments, physical and chemical analyses of the materials and structural evaluations. Within this research, though, microclimatic analyses are forgotten in the vast majority of cases and, when studied, this is exclusively as a specific characteristic of the current situation. There is usually absent any consideration of its historic development and only reduced attention is given to how it could be modified starting from the actual consistency of the building, without any heating, ventilation and air-conditioning (HVAC) system.

This means that in past times the internal microclimate of each building was strictly connected to the specificities of: the territory in which the building stands; its architectural traditions, i.e., the amount of materials, techniques, tastes, etc.

During the pre-modern era, the desired microclimate had an essential priority: it was a significant objective, which guided designers' choices. Indeed, many strategies and solutions are described in 
the historic essays to obtain a specific indoor microclimate in buildings, and how even to ensure the optimal conditions for the conservation of the building itself and for the occupants' comfort. Instead, the introduction of HVAC systems seems to decouple the building design and material characteristics from its microclimatic performance.

\subsection{Research Aim}

We think that HVAC is certainly useful, but sometimes it is not enough: historically, and technical systems could have malfunctioning problems which can cause a failure of the visitors' comfort, or, worse, jeopardize the heritage preservation. Therefore, to guarantee the preventive conservation it must be associated to an accurate monitoring control.

Thanks to the different approach we are proposing, however, highly interesting data can be collected with reasonable costs and time investment and thus more effective restorations can be achieved. We are trying to put together indoor microclimate monitoring and history of the building, obtaining the concept of the Historic Indoor Microclimate (HIM).

In this article we will show how could be used the indoor microclimate monitoring control, associated to the virtual building and environmental simulation, in order to guarantee the preventive conservation of a building and the artefacts guarded inside it, and secondly, to ensure the thermal comfort of people.

\subsection{What Is the Historic Indoor Microclimate (HIM)?}

In historical buildings, mostly in those built before XX century, when HVAC systems were introduced, original indoor microclimate conditions were strictly dependent on the architectural, technological features and local techniques used to build them. We can affirm that each historical architecture has its own, and is characterized by, specific HIM.

Many studies have been conducted about indoor microclimate and comfort sensation within scientific literature $[1,2]$ and physical characteristics and instruments have been defined, especially in the heritage field [3-8]. Different study cases have been analysed [9,10], especially in relation to the indoor microclimate of museums [11-14], and norms have been elaborated [15,16], as well as specific indexes for the heritage field [17]. In this perspective, a historical role has been given to HVAC [18], and we tried to start to study it in different papers [19-21]. Nowadays, the virtual building simulation is increasingly used for the restoration project and with the aim of ensure a preventive conservation, considering the past conditions of a building too [22].

The definition of HIM, as reported here, is strongly related to the changes of the indoor microclimate over time and to changes in the studied building. Hence, we study the history and evolution of indoor microclimate in architectures, alongside with the variation of their physical characteristics, its shape, on one hand, (with regard to enlargement or reduction of the building or partially demolitions, etc.) and, on the other hand, in relation to the presence of proto-systems such as fireplaces or stoves and, later, proper HVAC systems. These studies concern as well cultural characteristics affecting on the historic microclimate and on the building itself, such as the use of clothes, functions, habits and rituals of the inhabitants and even energy sources.

The HIM, like every microclimate, is a product of the interaction between the main parameters: temperature $(\mathrm{T})$ and relative humidity $(\mathrm{RH})$, with some other, e.g., air speed; solar radiation; $\mathrm{CO}_{2}$; etc. To these parameters, time has to be added, because it is exactly from the relation between specific indoor microclimates in different times that springs out the concept of HIM. We are talking about multidisciplinary research that could concern many areas of interest: artefact and historic building conservation; comfort in historic buildings; building physics; history of architecture, to the history of culture. As it is well known, knowledge about restoration increased much since the beginning of the discipline, at the beginning of XIX century, both in the number of study cases and in the theoretical approaches. Moreover, a lot of different disciplines and disciplinary sectors have been involved since then, such as the history of architecture and the chemistry of materials and physics. 
To better understand what we intend for HIM, we can divide it into:

A. Original Indoor Microclimate (OIM) i.e., the historically original microclimate, that characterized the building when it has been built. Simulations based on historic, climatic and architectural data allow to understand and reconstruct how the OIM was, with the help of historical information on the period of the building construction. The knowledge of OIM is relevant to speculate on the relation between the original microclimate and possible deterioration and decay that can appear on the building. This because, very often, OIM is the microclimate that can ensure the best conservation of the building itself;

B. Subsequential Indoor Microclimate (SIM): the different microclimates that are supposed to have happened in historic times in the building, related to variations in the structure and management of the building. All these data can be deduced from historic and architectural studies as well as from research on the phases of building construction and from the survey of the building itself, including plants, paintings, written reports, etc.;

C. Actual Indoor Microclimate (AIM): the current microclimate, determined by the state of the building in the moment in which we record it. This has to be measured and surveyed with instruments placed in loco during the monitoring phase; the collected data can be used to validate the ones obtained by the virtual model (comparing each other).

\section{Materials and Methods}

The subject of our research is the HIM.This paper reports the application of a methodology in four case studies.

We worked on two main methods to perform these studies: research into historic archives and building simulation (BS) within virtual environmental building. This latter study method creates a virtual model of the building based on its original configuration, with no addition or successive modifications and use it to simulate the past microclimate of buildings. The results obtained with this method allow to understand the characteristics of the original indoor microclimate and use this information to develop considerations useful to restoration projects.

Our research method include:

- to study the history of a building, including its historical use destinations;

- geometrical and technological relief (HVAC included);

- indoor monitoring campaign, including the positioning of probes;

- Building simulation of state of art (AIM) and virtual environment;

- Model validation (comparing measured data with simulated ones);

- Virtual scenarios: trough the BS we can simulate the buildings' indoor microclimate in the past, in the future, and following several management and structural scenarios (modifying the current visitor affluence, the building's structure, the management of opening and closing of windows, the weather data, etc.)

It is not always possible to do all these steps: it depends on the case study, management, funds, team, etc. Nevertheless, this methodology has been adopted for all the case studies presented in this paper.

\section{Results: Learning from Our Case Studies}

Up to the present, we have monitored the indoor microclimate in several buildings and analyzed the collected data, always with the aim of the preventive conservation. In this article we will report some representative results of our research, about four case studies. The buildings at hand are historic buildings, built between the XV and XVIII centuries, in different regions of Italy and in all of them the HVAC system is not activated. 


\subsection{Malatestiana Library, Cesena, Italy}

The Malatestiana Library was built in 1454 by the architect Matteo Nuti. The building has no HVAC from its origins (not even light system; just antitheft and fire alarm) and the monitoring we are showing relates to the period between March and October 2013. Malatestiana Library's AIM probably is very similar to its OIM because, excluding outdoor historic thermal conditions, that underwent some changes from the XV Century, nothing which could affect the indoor microclimate was modified. The result is that the particular indoor microclimate of this building still permits the conservation of the wooden plutea and of the parchment manuscripts after more than 500 years. The absence of any HVAC system did not negatively affect the manuscript conservation. On the contrary, Nuti's project successfully achieved the goal to create the perfect situation to preserve its contents. The presence of an attic and a ground level allows direct irradiation from above to be avoided and reduces the heat exchange from below (Figure 1). This outcome of Renaissance architectural knowledge is an architecture that maintains a high efficiency level with no expenses in terms of plants. The Figure 2 shows an example of building simulation results: we know that the indoor air temperature is nor the only data which represents HIM, but in order to explain our research, we believe that this example data should synthesize it.

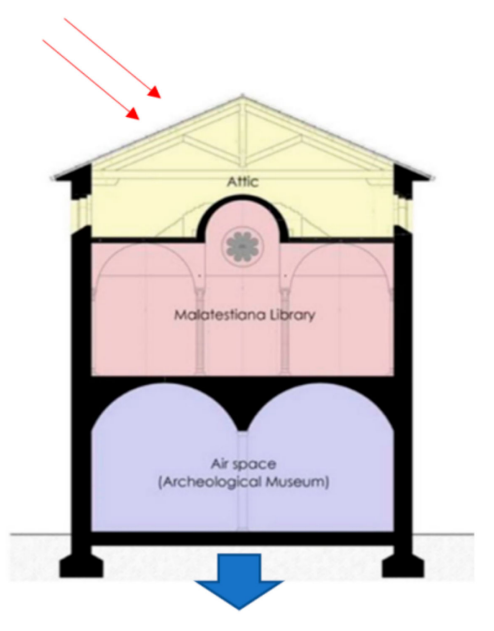

Figure 1. Section of Malatestiana Library.

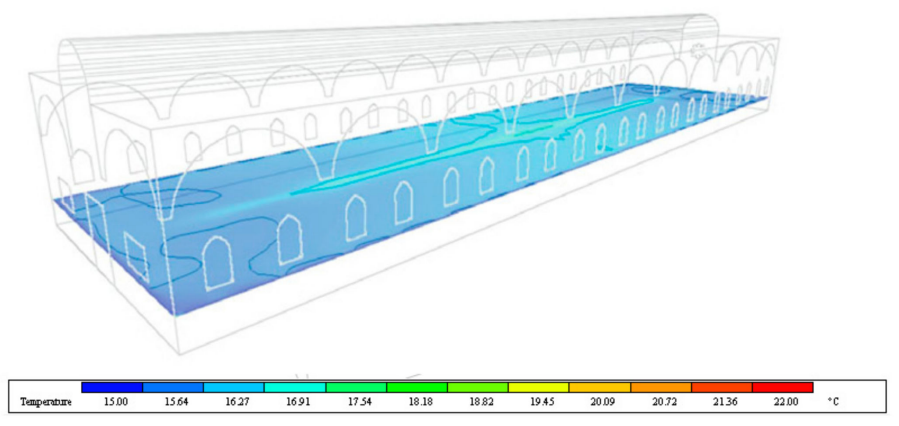

Figure 2. Building simulation, air temperature. Example of results.

We learn that this building, which works as a perfect machine, requires a very precise management of its more than 44 windows opening, to maintain the optimal indoor microclimate of the library. Moreover, we proposed an Indoor Microclimate Monitoring Guideline to the building manager and public administrator, thanks to the help of the virtual simulated scenarios (Figures 2 and 3). 


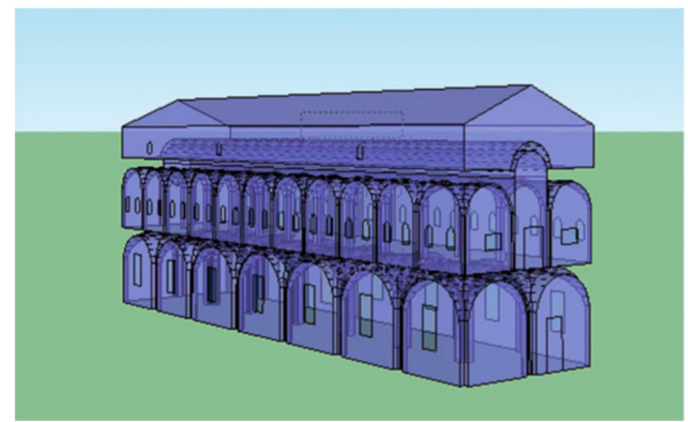

Figure 3. 3D SketchUp model of Malatestiana Library.

\subsection{Valinotto Sanctuary, Carignano, Italy}

This shrine is one of the most interesting examples of Piedmontese baroque architecture, from the project of Bernardo Vittone. The building has no HVAC plant. The monitoring was carried out from January to June 2015. The geometry of this building is quite complex, as shown in Figure 4 . During the monitoring campaign the focus has been on the parameters of the air temperature and relative humidity.

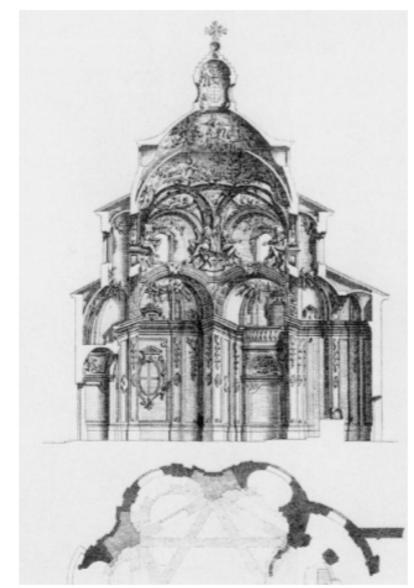

Figure 4. Map and section of Valinotto Sanctuary, from Vittone 1766 II, tav. LXXVIII.

The two probes which record the air temperature were placed one above the other, on the same vertical line but at different altitudes within the church: at $1.65 \mathrm{~m}$ and $5.65 \mathrm{~m}$ from the ground, with a distance between them of $4.00 \mathrm{~m}$. That permitted careful evaluation of the air stratification. The difference in measured data (Figure 5) by those probes is a proxy of air stratification and convective motions and increases with internal temperature during spring. Indeed, the phenomenon does not appear strictly dependent on external temperature, though, otherwise there wouldn't be any difference between upper and lower levels.

Moreover, the entrance of the sunbeams in the highest part of the building and on the ceiling, due to the influence of solar radiation, causes an overheating of those areas.

We learn that this problematic situation appears to be due to the loss in functionality of the system of windows present on the architectural body that are now blocked. The shape of the building makes the building's conformation develop vertically in particular, and that promotes rising currents of warm air and air convective movements. A most frequent windows opening can guarantee a more adequate conservation of the complex, indeed a different management could resolve the stratification in the upper levels of this building. The presence of different indoor microclimatic conditions, as in the case of air stratification, involves a mayor risk of damage related to concentration of dust, highest levels of air temperature near the ceiling, resulting relative humidity levels, etc. 


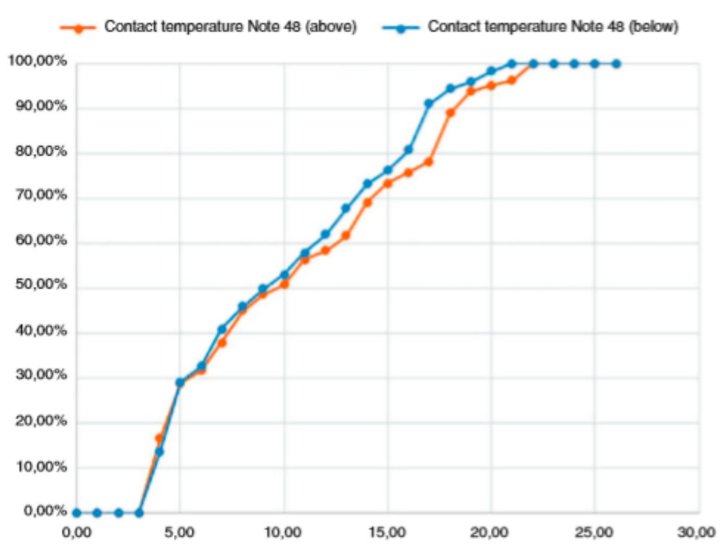

Figure 5. Comparison between percentage of cumulated frequency of indoor air temperature for the two probes, upper and lower. Data have been collected through a contact temperature sensor.

\subsection{Villa La Petraia, Florence, Italy}

The Villa, built at the end of XV century, is attributed to Buontalenti. the current shape is the result of years of transformations: the central courtyard, was covered in 1872, by a glass and metal structure (Figure 6). Nowadays, the heating system installed in the building is not working. The results of this study show the consequences of the covering, that changed deeply the original microclimate of the villa and creates risks to the conservation of the historical and artistic heritage contained in there (AIM). The modelling permits evaluation of the benefits of the reactivation of the cover's windows, recreating the HIM and through the simulation it has been possible to compare the current microclimatic condition of the whole building, due to the introduction of the cover, to the original without the cover. Figure 7 shows an example of the current condition of one of the studied parameters, relative humidity, in three studied rooms of Villa Petraia.

We learn that the introduction of the cover highly increases the indoor temperature of the building: we have differences from a minimum between $2-3^{\circ} \mathrm{C}$ in winter and a maximum of $10^{\circ} \mathrm{C}$, in summer (Figure 8).

Moreover, also in this case study, a correct management of the windows system could improve the $\mathrm{T}$ conditions, because the opening and closing of the windows (choosing in which hours and how long) strongly affects the air circulation and so the level of the relative humidity too. Indeed, thanks to the monitoring campaign (22/07/2015-23/03/2016) and the building environmental simulations (through the software IES.VE), it has been possible to propose a virtual scenario, with a repaired glass ceiling, equipped with an automated system, which allows us to open and close them: in this way temperatures become $1.5-2{ }^{\circ} \mathrm{C}$ lower (Figure 9 ).

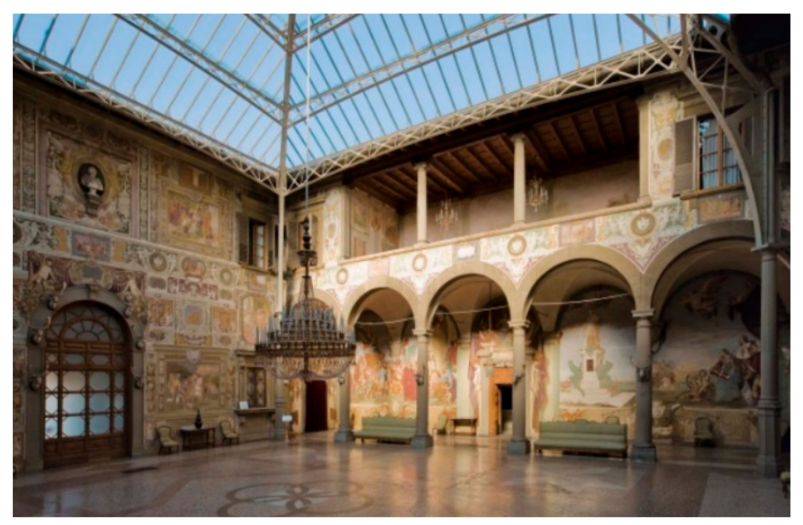

Figure 6. The glass and metal cover in the courtyard of Villa La Petraia. 


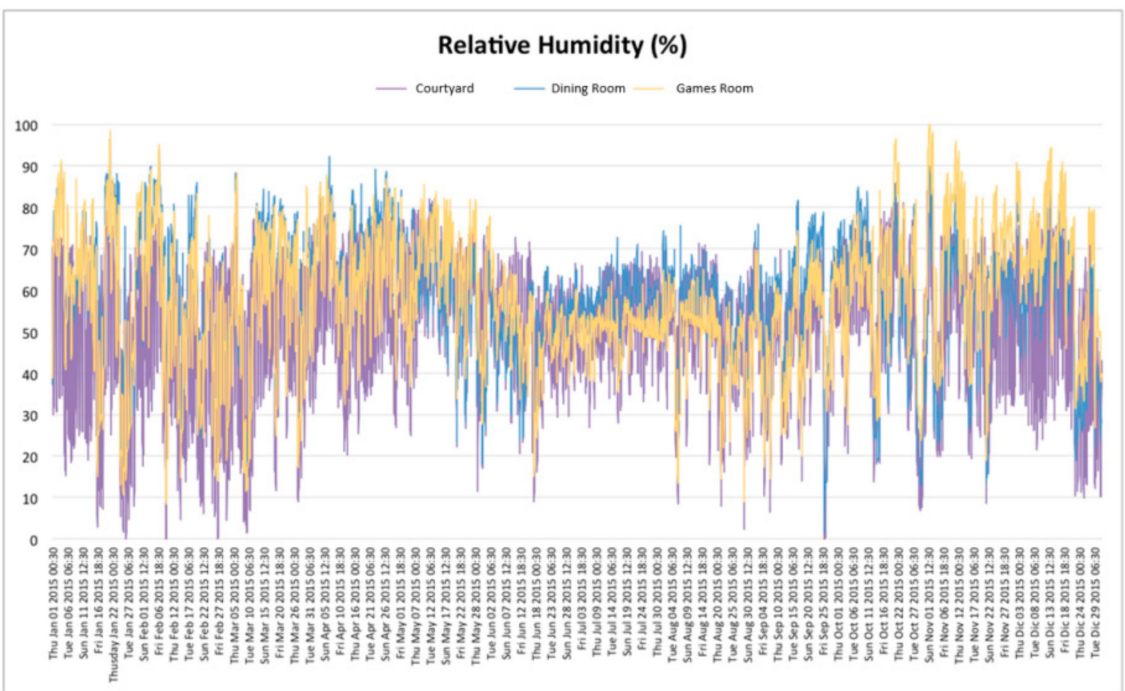

Figure 7. Comparison between the trends of Relative Humidity in three studied rooms of Villa La Petraia. (Building Simulation: current scenario).

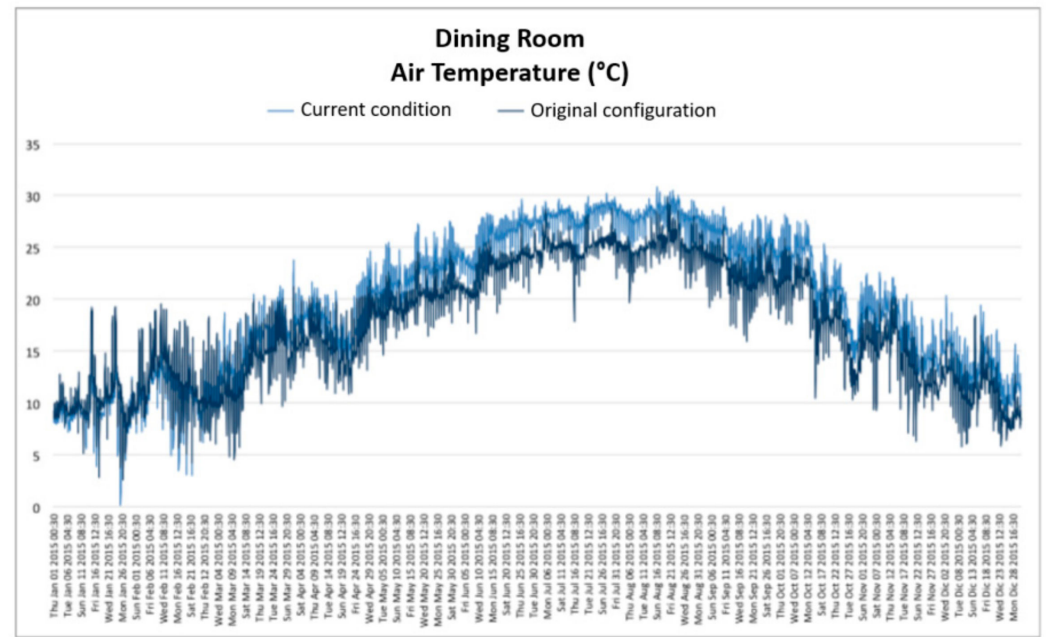

Figure 8. Comparison between the indoor air temperature data of the dining room with and without the cover.

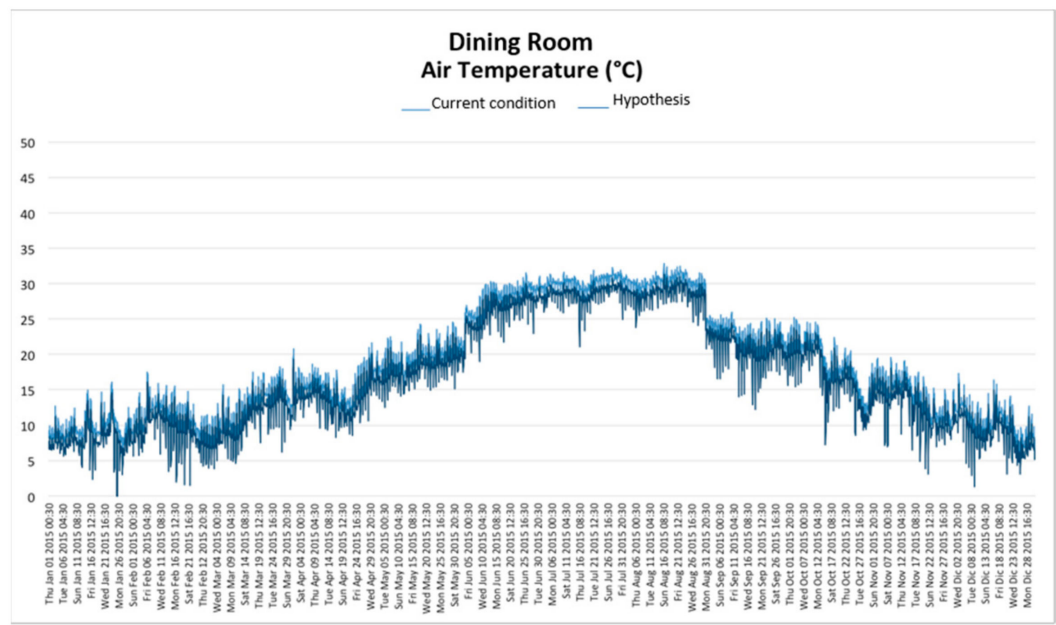

Figure 9. Comparison between the indoor air temperature data of the dining room with and without the mechanic window system. 


\subsection{Villa Barbaro, Maser, Italy}

Villa Barbaro, built between 1554-1560 by Andrea Palladio, today is partly used as a residential building, and partly as a museum: only six rooms are accessible to the public - here the HVAC system is idle-and three of those have been monitored during our monitoring campaign (17/06/2016-21/06/2016). Figure 10 shows $\mathrm{T}$ and $\mathrm{RH}$ data recorded by probes in two of those rooms. The goal was to verify and simulate the state of conservation of the artefacts and the occupants' comfort.

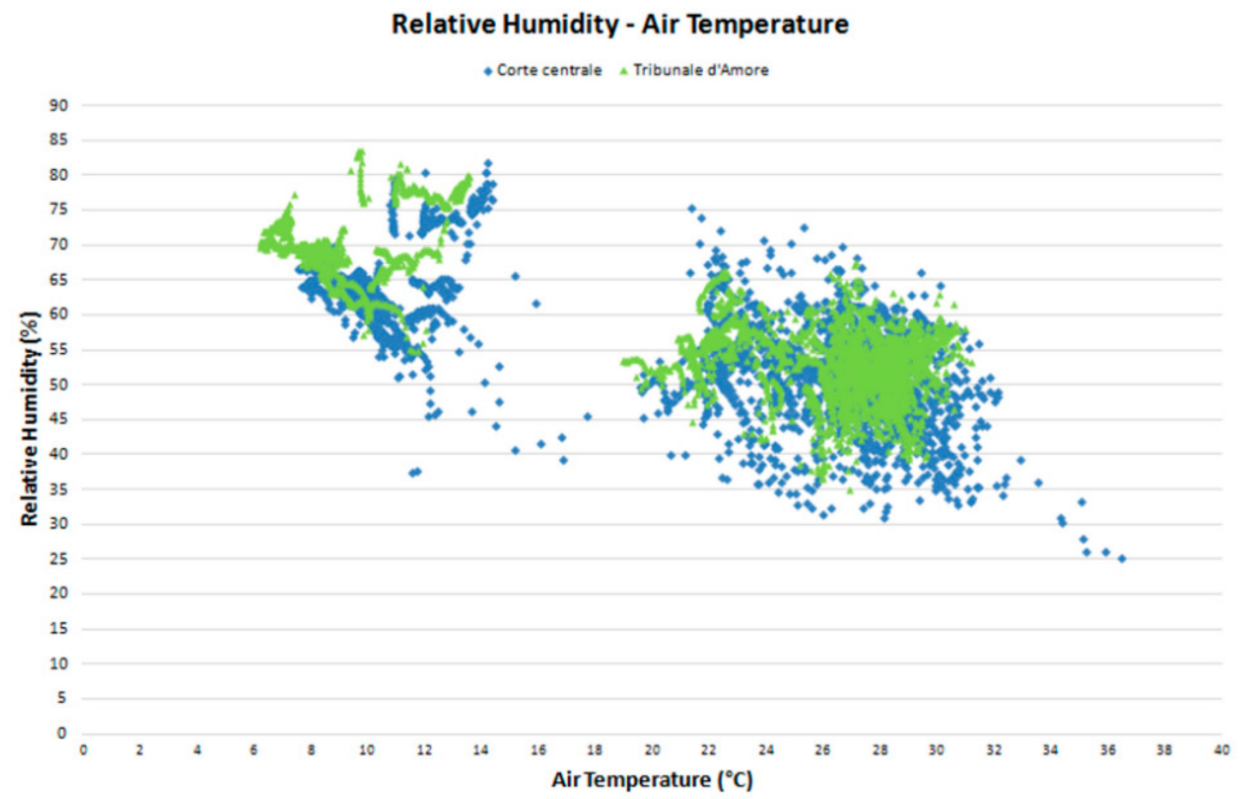

Figure 10. Current ratio between temperature $(\mathrm{T})$ and relative humidity $(\mathrm{RH})$ in the Croce Centrale room and in the Tribunale d'amore room. (Probes data).

About the comfort, the recorded data showed that the indoor microclimate conditions do not comply with the "modern habits": sometimes temperatures reach about $29{ }^{\circ} \mathrm{C}$ in summer and $12{ }^{\circ} \mathrm{C}$ in winter. But, in this case, the visitors' comfort could be overshadowed because the visit duration is just about $40 \mathrm{~min}$. Things become more complicated when we talk about artefacts' conservation. The building simulation and the data collected by probes, show that parameters such as relative humidity and air temperature, do not coincide with the standards suggested [23] for the conservation of typical materials guarded inside Villa Barbaro (Figures 11 and 12), which is mostly characterized by the presence of frescoes. However, all the artefacts and the frescoes too (Figure 13), appear perfectly conserved and, as mentioned in EN15757/2010, if the indoor microclimate is not causing any decay, it should not be changed.

We learn that through building simulation it is possible to assume a scenario with HVAC on, set to comply with standards, but we must remind that if a building or an artefact has been conserved in a specific environment for years, in this case for centuries, a sudden change of the microclimatic conditions could jeopardise its preservation: before making choices for those delicate buildings, their whole history (use, architectonical changes, etc.) must be known and that of the artefacts guarded inside them. 


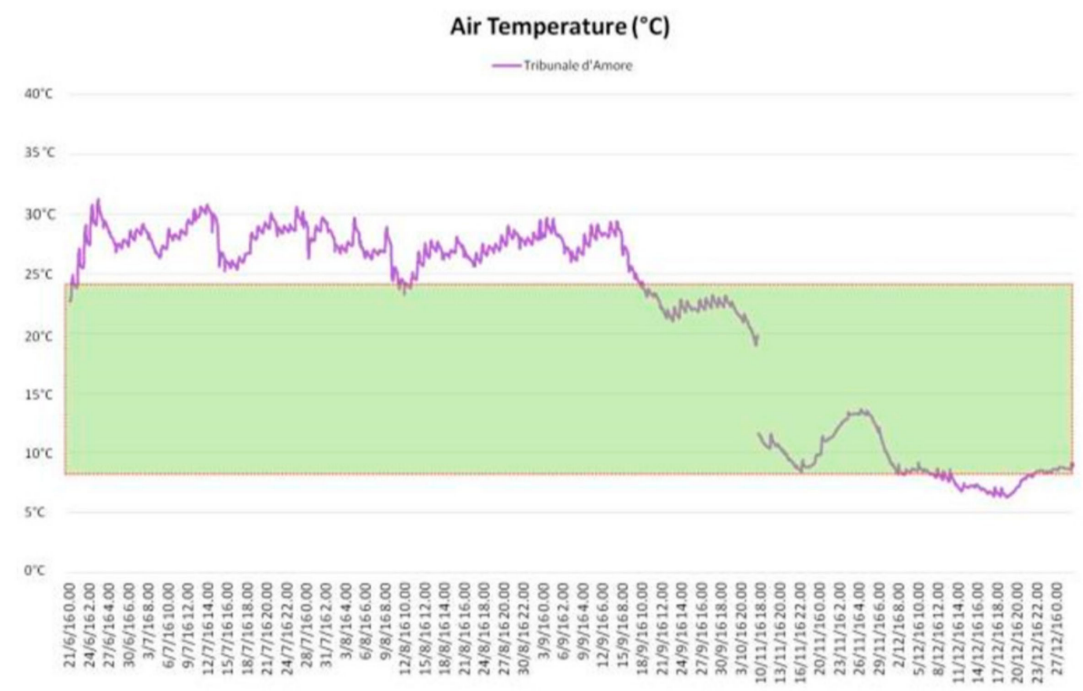

Figure 11. Current air temperature in the monitored Tribunale $\mathrm{D}^{\prime}$ Amore toom. The green rectangle indicates the ranges established by standards for the suggested temperature to conserve frescoes.

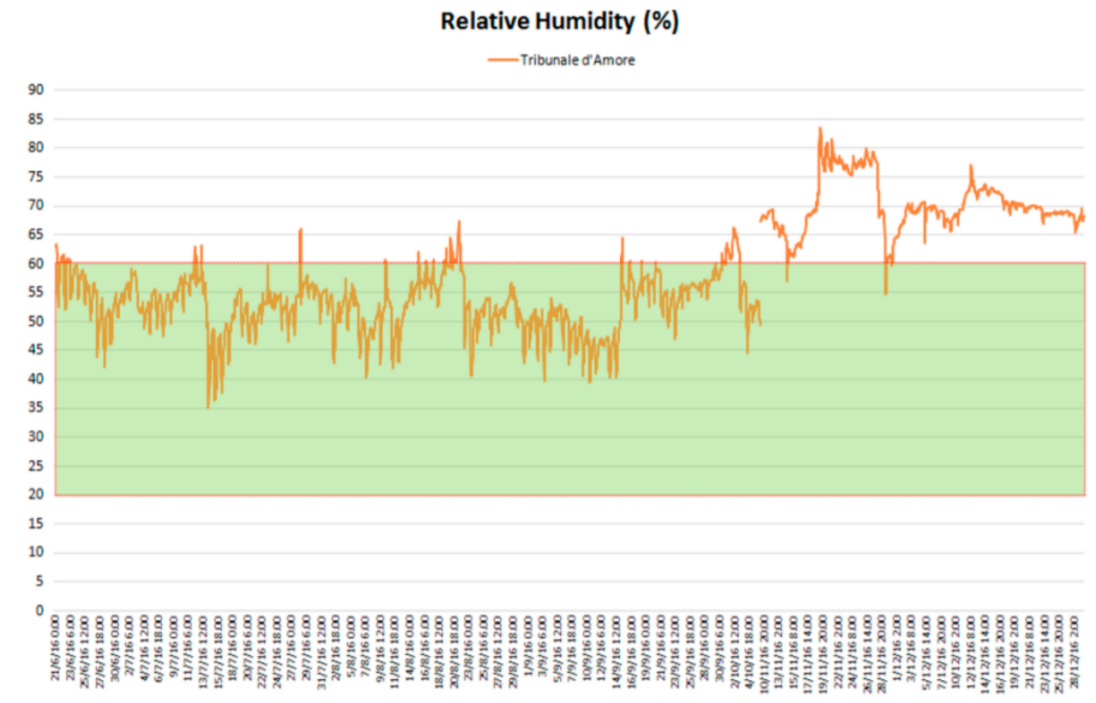

Figure 12. Current relative humidity in the monitored Tribunale D'Amore toom. The green rectangle indicates the ranges established by standards for the suggested relative humidity to conserve frescoes.
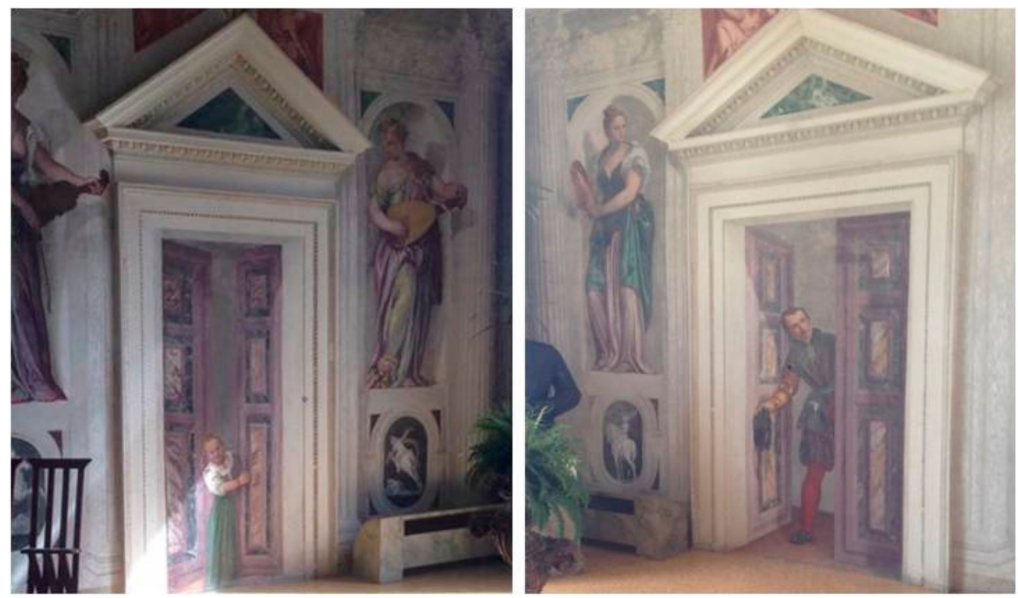

Figure 13. Indoor frescoes, in the Croce Centrale room. 


\section{Discussion}

HIM is relevant for the knowledge concerning architectures because, when coupled with other historic data, it helps us to understand the functioning of many heritage buildings. It also makes interesting contributions to the conservation projects and has to be considered as relevant as the structural data or the physical-material data. Knowledge of HIM allows us to assess the effects of microclimatic changes in relation to decay phenomena; it gives suggestion on how to preserve the architecture. With respect to this, the corpus of data concerning indoor microclimate results in being incredibly significant to understand the mechanisms of decay of the materials of buildings which, in our opinion, should not be neglected. Restoration is the last step to be undertaken; as highlighted by Cesare Brandi and Giovanni Urbani, it should be considered extreme, and adopted as a solution only in those cases where the degree of the building's decay is such that no other conservation strategy is feasible.

Moreover, HIM studies should be defined as intangible heritage [18] research, because this approach is totally in line with the UNESCO (United Nations Educational, Scientific and Cultural Organization) definition of Intangible Cultural Heritage: "cultural heritage does not end at monuments and collection of objects. Thanks to the virtual building simulation, it is possible to simulate the indoor environment and the thermal comfort of people in the present, past and future, which depends considerably on the HVAC systems, the use of the building, and people's activity and clothes.

Finally, we aim to continue and promote other research on these kinds of buildings and issues to highlight how and how much the role of heritage buildings' indoor microclimate, the presence or not of the HVAC system in them, and the knowledge of their history both in terms of the intended use and their architectonical shape and configuration, affect the buildings' conservation.

\section{Conclusions}

The authors believe that HIM should be a central study subject for researchers dealing with historic architecture, because it helps to define strategies to enhance knowledge, conservation and the fruition of architecture itself. HIM is an intangible heritage which has to be studied and preserved in its own right.

We think that indoor monitoring, combined with the virtual building simulation, is one of the most important approaches to ensure preservation without affecting the materiality of architecture. Moreover, it is a useful basis on which to build a restoration project, and it helps in finding a compromise and setting priorities from the interaction of accessibility, conservation, and occupants' comfort.

Author Contributions: Conceptualization, K.F., M.P. and A.B.; Data curation, K.F., M.P. and A.B.; Formal analysis, K.F., M.P. and A.B.; Investigation, K.F., M.P. and A.B.; Methodology, K.F., M.P. and A.B.; Project administration, K.F., M.P. and A.B.; Resources, K.F., M.P. and A.B.; Software, K.F., M.P. and A.B.; Supervision, K.F., M.P. and A.B. All the authors contributed equally to this work with regard to all the statements.

Funding: This research received no external funding.

Acknowledgments: The authors acknowledge arch. Leila Signorelli and ing. Cinzia Magnani for their help in Villa Medici research, Donna Diamante(†) for her friendliness to opening Villa Maser, archh. Agostino Magnaghi and Andreina Milan for their support during research about Santuario del Valinotto.

Conflicts of Interest: The authors declare no conflict of interest.

\section{References}

1. Fabbri, K. Indoor Thermal Comfort Perception: A Questionnaire Approach Focusing on Children; Springer: Berlin/Heidelberg, Germany, 2015. [CrossRef]

2. Fabbri, K. Thermal comfort evaluation in kindergarten: PMV and PPD measurement through datalogger and questionnaire. Build. Environ. 2013, 68, 202-214. [CrossRef]

3. Pretelli, M.; Fabbri, K. Historic Indoor Microclimate. In Historic Indoor Microclimate of the Heritage Buildings; Springer: Berlin/Heidelberg, Germany, 2018; pp. 73-83. [CrossRef] 
4. Fabbri, K.; Pretelli, M. Heritage buildings and historic microclimate without HVAC technology: Malatestiana Library in Cesena, Italy, UNESCO Memory of the World. Energy Build. 2014, 76, 15-31. [CrossRef]

5. Camuffo, D. Microclimate for Cultural Heritage; Elsevier: Amsterdam, The Netherlands, 1998.

6. Thomson, G. The Museum Environment, 2nd ed.; Elsevier: London, UK, 1986.

7. Ashley-Smith, J.; Burmeister, A.; Eibl, M. Climate for Collections: Standards and Uncertainties; Archetype Publication: Munich, Germany, 2013.

8. Brimblecombe, P. Heritage climatology. In Climate Change and Cultural Heritage; Lefevre, R.-A., Sabbioni, C., Eds.; Edipuglia: Bari, Italy, 2010; pp. 57-64.

9. D'Agostino, V.; D'Ambrosio Alfano, F.R.; Palella, B.I.; Riccio, G. The museum environment: A protocol for evaluation of microclimatic conditions. Energy Build. 2015, 95, 124-129. [CrossRef]

10. Litti, G.; Audenaert, A.; Fabbri, K. Indoor Microclimate Quality (IMQ) certification in heritage and museum buildings: The case study of Vleeshuis museum in Antwerp. Build. Environ. 2017, 124, 478-491. [CrossRef]

11. La Gennusa, M.; Lascari, G.; Rizzo, G.; Scaccianoce, G. Conflicting needs of the thermal indoor environment of museums: In search of a practical compromise. J. Cult. Herit. 2008, 9, 125-134. [CrossRef]

12. Ferdyn-Grygierek, J. Monitoring of indoor air parameters in large museum exhibition halls with and without air-conditioning systems. Build. Environ. 2016, 107, 113-126. [CrossRef]

13. Ferdyn-Grygierek, J. Indoor environment quality in the museum building and its effect on heating and cooling demand. Energy Build. 2014, 85, 32-44. [CrossRef]

14. Pavlogeorgatos, G. Environmental parameters in museums. Build. Environ. 2003, 38, 1457-1462. [CrossRef]

15. EN 15759-1:2011. Conservation of Cultural Property-Indoor Climate-Part. 1: Guidelines for Heating Churches, Chapels and Other Places of Worship Contents; UNI (Italian National Unification): Milano, Italy, 2011.

16. EN 15757:2010. Conservation of Cultural Property—Specifications for Temperature and Relative Humidity to Limit Climate-Induced Mechanical Damage in Organic Hygroscopic Materials; NSAI: Dublin, Ireland, 2010.

17. Litti, G.; Audenaert, A.; Braet, J.; Fabbri, K.; Weeren, A. Synthetic scan and simultaneous index aimed at the Indoor Environmental Quality evaluation and certification for people and artworks in heritage buildings. Energy Procedia 2015, 78, 1365-1370. [CrossRef]

18. Hawkes, D. Architecture and climate. In An Envinronmental History of British Architecture; Routledge: London, UK; New York, NY, USA, 2012.

19. A consulting/preserving machine for manuscripts: The Malatestiana Library in Cesena. In Proceedings of the 6th International Congress "Science and Technology for the Safeguard of Cultural Heritage Mediterranean Basin", Athens, Greece, 22-25 October 2013.

20. Fabbri, K. Energy incidence of historic building: Leaving no stone unturned. J. Cult. Herit. 2013, 14, e25-e27. [CrossRef]

21. Pretelli, M.; Fabbri, K. New Concept of Historical Indoor Microclimate-Learning from the Past for a More Sustainable Future. Procedia Eng. 2016, 161, 2173-2178. [CrossRef]

22. Eibl, M.; Burmester, A. Learning from history. Historic indoor climate conditions and climate control strategies. In Proceedings of the Climate for Collections, Standards and Uncertainties, Munich, Germany, 2013; pp. 217-232.

23. UNI 10820. Works of Art of Historical Importance-Ambient Conditions or the Conservation-Measurement and Analysis; UNI (Italian National Unification): Milano, Italy, 1999.

(C) 2019 by the authors. Licensee MDPI, Basel, Switzerland. This article is an open access article distributed under the terms and conditions of the Creative Commons Attribution (CC BY) license (http://creativecommons.org/licenses/by/4.0/). 